\title{
The Financial Capacity Assessment of Major Grain Producing Areas-Empirical Analysis Based on Shandong Country Data
}

\author{
Zhongkai Liu \\ School of Economics, Jinan University, Guangzhou, China \\ Email: Izk1107@126.com
}

Received 19 October 2015; accepted 14 November 2015; published 17 November 2015

Copyright $@ 2015$ by author and Scientific Research Publishing Inc.

This work is licensed under the Creative Commons Attribution International License (CC BY). http://creativecommons.org/licenses/by/4.0/

(c) (i) Open Access

\begin{abstract}
In this paper, starting at the definition of government financial capacity, building financial capacity evaluation system through factor analysis, and given that the fiscal capacity is unbalanced not only between grain producing areas and non-grain producing areas, but also among grain producing areas. Grain producing areas' economic development level influences financial capacity. Non-grain producing areas' supply of public goods does not match with economic development level. Then, some suggestions are submitted.
\end{abstract}

\section{Keywords}

\section{Grain Producing Areas, Financial Capacity, Fiscal Capacity Equalization}

\section{Introduction and Literature Review}

China totally has 13 major grain producing areas. Lili Gu and Qinghai Guo [1] had made profound analysis on the evolution and development of major grain producing areas, thought that the major grain producing areas had three characteristics: 1) the relatively concentrated on the space; 2) far distance from non-grain producing areas, and 3) significant differences in grain commodity rates. Shandong province is a major grain producing province, due to the different natural environment and city function orientation, major grain producing areas concentrated in the county. On the one hand, major grain producing areas must strengthen the food production and need pay a lot of money to maintain food security; on the other hand, it puts costs to develop economy in order to realize upgrading of industrial structure and effective supply of public goods, so compared to the non-grain producing areas and grain producing areas under greater financial stress. Therefore, its financial capacity status is worth exploring.

To evaluate grain producing areas fiscal capacity, it must clearly connotate the "fiscal capacity" first. Western

How to cite this paper: Liu, Z.K. (2015) The Financial Capacity Assessment of Major Grain Producing Areas-Empirical Analysis Based on Shandong Country Data. Open Journal of Social Sciences, 3, 207-214.

http://dx.doi.org/10.4236/jss.2015.311025 
studied more about "the government capacity", but the reference of "fiscal capacity" was relatively rare. There was also no exact definition of "fiscal capacity". Almond [2], John P. Coleman [3], R. T. Lenz [4] and Antony Brown [5] all thought that fiscal capacity was a part of the government capacity; Buchanan [6] studied the imbalance problem of fiscal capacity. He found that transfer payments from the central government to local government, to a certain extent, could change the fiscal capacity of a region. Other scholars, such as Tiebout [7], Oates [8] and Musgrave [9], studied how to distribute financial problems. Domestic scholars have had conducted extensive research on fiscal capability. Wenxing Li and Jiang Ying [10] argued that the local government financial capacity was the local government raises money on the basis of public rights to provide public goods. To meet the need of citizens, stable local public economy is reasonably redistributed. Xuejun Li and Shangxi Liu [11], with a new perspective of analyzing financial capacity, thought that it was not a simple financial scale, but a multi-dimensional concept. It not only related to the government resources, but also related to the government how to configure the resources of the financial system. It needed multi-angle analysis. They also put forward three levels to evaluate fiscal capacity: standard fiscal capacity, realistic fiscal capacity and potential fiscal capacity. Hongyou Lu and Zhilian Jia [12] argued that local fiscal capacity was the ability of local government drawing resources and effective supply of public goods. In a word, the generally accepted concept of fiscal capacity which referred to cover the fiscal absorbing ability and configure ability was embodied in focus of local government drawing financial resources, the allocation of resources and the effect from complete financial activities.

About fiscal capacity to measure; Qiang Li [13] used per capita fiscal expenditure and related indicators to measure regional fiscal capacity gap; Xiangling Wu and Xiaoying Deng [14] used self-financing rate and government budgetary revenues accounted for the proportion of GDP to measure the financial capacity, while Hanbo Liu, Gong Li and Yidan Xia [15] measured the country's fiscal capacity by per capita fiscal income; Hongyou Lu and Zhilian Jia set provincial government fiscal capacity evaluation index from fiscal absorbing ability and the ability of public goods supply; Ran Guang, Luzhao Yang and Xu Kun [16] built a comprehensive evaluation index system and measured county government financial capacity from aspects of the level of county economy, county economy benefit and the county economy growth potential; Yanglin and Xiaoyan Yuan [17] measured government fiscal capacity by a comprehensive evaluation index system, which was set up from aspects of the fiscal revenue, fiscal expenditure and self-sufficiency; as the deeper understanding of the fiscal capacity, a more comprehensive evaluation index system of fiscal capacity was gradually adopted.

To sum up, although domestic research on local fiscal capacity was more extensive, the research on fiscal capacity of major function area especially the study of the major grain producing areas was lacking. At the same time, the major grain producing areas are located in the west of Shandong province, which is similar to most of the major grain producing provinces located in China. So, fiscal capacity of the major grain producing areas in Shandong province is studied. It has universal significance for constructing fiscal capacity of the national major grain producing areas.

In this paper, starting at the definition of government financial ability, I build financial capacity evaluation system through factor analysis and select 25 producing counties in Shandong. In order to compare with nongrain producing areas, I select 5 non-grain producing counties and use 18 indicators to evaluate Shandong grain producing areas' financial capacity, given that the fiscal capacity is unbalanced not only between grain producing areas and non-grain producing areas, but also among grain producing areas. Grain producing areas' economic development level influences financial capacity. Non-grain producing areas' supply of public goods does not match with economic development level. Then, some suggestions are submitted.

\section{The Research Method and the Establishment of Evaluation Index System of Fiscal Capacity}

\subsection{Factor Analysis Method}

Factor analysis is an effective statistical analysis method. It can be easy get a few main factors to explain the original variables, by extracting from more complex variables and samples, so as to find out a few random variables, to describe the related or similar relationship between multiple variables or samples. The ultimate goal partly reflects the overall [18]. Government fiscal capacity is a complex, involving the multi-dimensional information. Through factor analysis, it can reduce a few common factors. It also reflects the original information of fiscal capacity. According to the factor score, an objective evaluation is made. So its principal component analy- 
sis is chosen. The model is set as: $(j=1,2$, and $3, \cdots, n, n$ is total number of original variables). $\mathrm{X}$ represents the original variable, after the standard treatment for $Z$, it can be in the form of a matrix for $Z=A F+U$. $F$ calls public factor, appears in each of the original variable linear expression; $a_{j i}$ calls factor loading, $\mathrm{U}$ calls special factors, represents parts of the original variables which cannot be explained by factors. $M$ represents the number of common factor of all variables.

\subsection{The Evaluation Index System of Fiscal Capacity}

Considering the principles of data availability, authoritative and operability, combine with major grain producing areas situation, which are less developed, with the large agricultural population, urbanization level is relatively low, so from aspects of the financial revenue ability, potential growth ability, expenditure ability and self-sufficiency ability, to establish the evaluation index system for major grain producing areas is more reality (Table 1).

The index of finance income ability mainly considered from factors of fiscal revenue sources, quantify potential growth ability is relatively complex, needed think of the whole society; While fiscal expenditure ability is not only reflected on the expenditure scale, but also expenditure structure of the public service, in which the most important are public health and education systems. Fangkun Xin [19] used the adult illiteracy rate (\%) to measure the quality of education, used the number of medical institution beds in every ten thousand people as indicators to measure clinical outcomes, due to the availability of data from the county, we can use the proportion (\%) of livelihood expenditure in public expenditure and the number of primary teachers in every one thousand people instead; And index of self-sufficiency ability reflects the ability of government how much independent to raise revenue.

\section{Empirical Research on the Fiscal Ability of Major Grain Producing Areas}

\subsection{Data Sources}

According to annual output of grain in China, and with reference to the ministry of agriculture "the national grain production counties "list in 2013, 25 counties in Shandong were selceted; In order to compare with nongrain producing areas, five non-grain producing counties which are: Huangdao, Shizhong, Zhangdian, Laishan,

Table 1. The evaluation index system of fiscal capacity.

\begin{tabular}{|c|c|c|}
\hline Target & Level & Indicators \\
\hline \multirow{18}{*}{$\begin{array}{l}\text { fiscal capacity of major grain } \\
\text { producing areas }\end{array}$} & \multirow{4}{*}{ financial revenue ability } & $X_{1}$ GDP \\
\hline & & $X_{2}$ public budget income \\
\hline & & $X_{3}$ public budget revenues accounted for the proportion of GDP \\
\hline & & $X_{4}$ per capita public budget income \\
\hline & \multirow{8}{*}{ potential growth ability } & $X_{5}$ per capita net income of farmers \\
\hline & & $X_{6}$ industrial gross output \\
\hline & & $X_{7}$ social consumer goods retail sales \\
\hline & & $X_{8}$ total exports \\
\hline & & $X_{9}$ the rural and urban residents 'deposit balance \\
\hline & & $X_{10}$ Completed investment in fixed assets \\
\hline & & $X_{11}$ the financial institutions loan balance \\
\hline & & $X_{12}$ land area per capita \\
\hline & \multirow{4}{*}{ expenditure ability } & $X_{13}$ the public finance budget expenditure \\
\hline & & $X_{14}$ per capita the budget expenditure \\
\hline & & $X_{15}$ the proportion of livelihood expenditure in public expenditure \\
\hline & & $X_{16}$ the number of primary teachers in every one thousand people \\
\hline & \multirow{2}{*}{ self-sufficiency ability } & $X_{17}$ degree of fiscal self-financing \\
\hline & & $X_{18}$ tax accounted for the proportion of budget income \\
\hline
\end{tabular}


Taishan were selected. 18 evaluation indexes all come from 2009-2014 "Shandong statistical yearbook". Although data index dimension is different, all are positive indicators.

\subsection{The Empirical Analysis}

First do Bartlett test and KMO test by SPSS20.0, the results show KMO $=0.862$, which is bigger than 0.5, and get significant probability of $x^{2}$ statistics which is 0.000 ; the correlation between data is suitable for factor analysis. And four comprehensive factors respectively explain the ability of the original information are 53.385\%, $13.863 \%, 9.385 \%$ and $8.519 \%$, the cumulative variance contribution rate is $85.152 \%$; all eigenvalues are bigger than 1 . It shows that the 4 factors enough reflect the fiscal capacity of grain producing counties.

As is shown in Table 2, about interpretation total variance, the results showed $\mathrm{KMO}=0.862$, is bigger than 0.5 , and get significant probability of $x^{2}$ statistics is 0.000 ; the correlation between data is suitable for factor analysis. In order to make the relation between $Z_{j}$ and $F_{i}$ more significant, make maximum swivel of variance factor loading matrix A, component 1 has contributed 53.385\% of fiscal capacity, in which the gross domestic product (X1), industrial gross output (X6), total exports (X8), completed investment in fixed assets (X10) have large load, it is associated with the level of economic development of grain producing areas, so we called development factor. Component 2 has contributed 13.863\% of fiscal capacity, public budget revenues accounted for the proportion of GDP (X3), per capita public budget income (X4) and per capita the budget expenditure's (X14) load is bigger, reflect the government's fiscal balance, we named fiscal balance factor; component 3 has contributed 9.385\% of fiscal capacity, in which social retail sales of consumer goods (X7), the rural and urban residents deposit balance (X9), the financial institutions loan balance (X11), the proportion of livelihood expenditure in public expenditure (X15) and the number of primary teachers in every one thousand people (X16) load is bigger, reflect the level of public services and environmental factors, we named environmental factors; component 4 has contributed $8.519 \%$ of fiscal capacity, including per capita public budget income (X4), per capita net income of farmers (X5), and degree of fiscal self-financing ' $\mathrm{s}(\mathrm{X} 17)$ load is bigger, reflect the self-sufficiency ability of current state of the major grain producing areas, so we named self-financing factor.

As is shown in Table 3, about rotate component matrix, 18 evaluation indexes all come from 2009-2014 "Shandong statistical yearbook". Although data index dimension is different, all are positive indicators. We get 4principal factors to reflect the fiscal capacity of grain producing counties. In order to evaluate fiscal capacity comprehensively, using the formula to calculate the total score of 30 evaluation object, and give a rank:

$$
\mathrm{V}=53.385 \% \times \mathrm{F} 1+13.863 \% \times \mathrm{F} 2+9.385 \% \times \mathrm{F} 3+8.519 \% \times \mathrm{F} 4
$$

\subsection{The Result Analysis}

\subsubsection{Sequence Analysis}

As is shown in Table 4, about financial ability composite score and ranking of 30 counties of Shandong province, the overall fiscal capacity has a gradually decline trend from the northeast coast to southwest inland. First of all, combined with the geographical position and economic zone of various counties, we have a lateral overall analysis on this phenomenon.

1) The Shandong peninsula blue economic zone. Main producing counties Pingdu, Laixi, Zhucheng, Gaomi, Laizhou and non-main producing counties Huangdao, Laoshan, comprehensive financial capacity ranking top,

Table 2. Interpretation total variance.

\begin{tabular}{ccccccc}
\hline \multirow{2}{*}{ Component } & \multicolumn{3}{c}{ Initial eigenvalues } & \multicolumn{3}{c}{ Extraction sums of squared loading } \\
\cline { 2 - 7 } & Total & $\begin{array}{c}\text { \% of variance contribution of variance } \\
\text { contribution of variance \% }\end{array}$ & Cumulative \% & Total & \% of variance & Cumulative \% \\
\hline 1 & 9.609 & 53.385 & 53,385 & 7435 & 41,306 & 41,306 \\
2 & 2.495 & 13.863 & 67,248 & 2958 & 16,434 & 57,740 \\
3 & 1.689 & 9.385 & 76,633 & 2813 & 15,629 & 73,329 \\
4 & 1.353 & 8.519 & 85,152 & 1941 & 11,783 & 85,152 \\
\hline
\end{tabular}

Extraction method: principal component analysis. 
Table 3. Rotate component matrix.

\begin{tabular}{|c|c|c|c|c|}
\hline \multirow{2}{*}{ Evaluation index } & \multicolumn{4}{|c|}{ Principal factor } \\
\hline & $F_{1}$ & $F_{2}$ & $F_{3}$ & $F_{4}$ \\
\hline$X_{1}$ & 0.958 & -0.003 & 0.085 & 0.221 \\
\hline$X_{2}$ & 0.914 & 0.249 & 0.236 & 0.141 \\
\hline$X_{3}$ & 0.030 & 0.782 & 0.397 & -0.261 \\
\hline$X_{4}$ & 0.570 & 0.610 & 0.064 & 0.430 \\
\hline$X_{5}$ & 0.493 & 0.398 & 0.115 & 0.669 \\
\hline$X_{6}$ & 0.929 & 0.038 & 0.143 & 0.049 \\
\hline$X_{7}$ & 0.643 & 0.024 & 0.578 & 0.335 \\
\hline$X_{8}$ & 0.918 & 0.064 & -0.168 & 0.031 \\
\hline$X_{9}$ & 0.723 & 0.247 & 0.542 & 0.111 \\
\hline$X_{10}$ & 0.926 & 0.129 & 0.064 & 0.167 \\
\hline$X_{11}$ at the end of the financial institutions loan balance & 0.420 & 0.326 & 0.786 & 0.038 \\
\hline$X_{12}$ & 0.261 & 0.075 & -0.710 & -0.158 \\
\hline$X_{13}$ & 0.891 & 0.258 & 0.234 & -0.089 \\
\hline$X_{14}$ & 0.587 & 0.671 & 0.007 & 0.257 \\
\hline$X_{15}$ & 0.011 & -0.882 & 0.770 & -0.144 \\
\hline$X_{16}$ & 0.336 & 0.382 & 0.794 & -0.191 \\
\hline$X_{17}$ & 0.344 & 0.327 & 0.287 & 0.634 \\
\hline$X_{18}$ & 0.042 & 0.089 & 0.040 & 0.675 \\
\hline
\end{tabular}

Extraction method: principal component analysis.

belongs to the body region of Shandong peninsula blue economic zone. It's also the important part of the national marine development strategy and coordinated regional development strategy; located in the eastern coastal, geographical position is superior. Relying on Qingdao leading economic radiation effect, the social economy and the integration of urban and rural development is rapid, financial ability is stronger.

2) Central of traditional manufacture areas. Main producing counties Zouping, Tengzhou, Zhangqiu, Feicheng, Daiyue, Qihe, Linyi and non-main producing counties Zhangdian, Taishan, Shizhong located in Shandong traditional central industrial zone, Jinan and Zibo as the leader of those districts, some counties in rich mineral resources, has a good foundation of industry, which are the gathering place of traditional coal production, smelting processing and other manufacturing industries. With the adjustment and upgrade of industrial structure, financial capacity is strengthening. However Jiyang, Pingyuan and Lingxian, the second industry is relatively backward, agriculture contribution is limited, so they are restricted by economic development level. Financial ability needs to improve.

3) The western plains. Dongming, Juan Cheng and Dingtao located in Heze, Yanggu, Guanxian belongs to Liaocheng city; Wenshang belongs to the city of Jining; Heze, Jining and Liaocheng belongs Huang-huai-hai plain, in addition to the economic growth faster Dongchang and tourism developed Qufu, compared with the eastern coastal economic region and central industrial zone these counties' industrial foundation is weak, economic development level is backward, food production has a long history. It is traditional agricultural area and its fiscal capacity lag behind other districts.

4) Yimeng mountain area. Yimeng mountain area are not all mountains, plains, hills and mountains each accounted for a third; Junan and Cangshan have the foundation of traditional agriculture. In recent years, they depend on the development of logistics industry in Linyi, policy support to the old revolutionary base areas, there is a breakthrough in economic development, and fiscal capacity increase steadily, but it still have obvious gap compared to the east. 
Table 4. Score and rank of 30 counties fiscal capacity.

\begin{tabular}{|c|c|c|c|c|c|c|}
\hline Rank & Countries & $F_{1}$ & $F_{2}$ & $F_{3}$ & $F_{4}$ & Score \\
\hline 1 & Huangdao & 4.547 & -0.138 & -1.087 & -0.215 & 2.288 \\
\hline 2 & Zhaodian & 0.687 & -0.081 & 3.536 & 1.262 & 0.795 \\
\hline 3 & Pingdu & 0.805 & -0.038 & -0.321 & 0.932 & 0.474 \\
\hline 4 & Zhouping & 0.651 & 0.398 & 0.629 & -0.164 & 0.447 \\
\hline 5 & Zhucheng & 0.680 & 0.329 & 0.239 & -0.051 & 0.427 \\
\hline 6 & Laizhou & 0.367 & 1.083 & -0.440 & 0.836 & 0.377 \\
\hline 7 & Tengzhou & 0.476 & -0.359 & 1.507 & -0.092 & 0.338 \\
\hline 8 & Zhangqiu & 0.337 & -0.019 & 0.078 & 0.831 & 0.255 \\
\hline 9 & Dongchang & -0.146 & 2.925 & 1.771 & -2.840 & 0.251 \\
\hline 10 & Laixi & 0.322 & 0.349 & -0.818 & 0.741 & 0.207 \\
\hline 11 & Gaomi & 0.214 & 0.062 & -0.094 & -0.002 & 0.114 \\
\hline 12 & Feicheng & 0.081 & -0.517 & 0.406 & 0.723 & 0.071 \\
\hline 13 & Laishan & 0.053 & 3.407 & -1.432 & 1.850 & 0.050 \\
\hline 14 & Qihe & -0.184 & -0.348 & -0.849 & 0.208 & -0.208 \\
\hline 15 & Daiyue & -0.013 & -0.521 & -0.224 & -1.281 & -0.209 \\
\hline 16 & Taishan & 0.337 & -0.0196 & 0.078 & 0.831 & -0.212 \\
\hline 17 & Lunan & -0.204 & -0.195 & -0.333 & -1.106 & -0.262 \\
\hline 18 & Shizhong & -0.322 & 0.561 & 0.804 & -0.048 & -0.294 \\
\hline 19 & Qufu & -0.671 & -0.597 & 0.093 & 1.151 & -0.335 \\
\hline 20 & Linyi & -0.359 & -0.380 & -0.611 & -0.529 & -0.347 \\
\hline 21 & Cangshan & -0.282 & -0.951 & 0.152 & -1.064 & -0.358 \\
\hline 22 & Jiyang & -0.714 & 0.745 & -1.094 & 0.203 & -0.363 \\
\hline 23 & Dongming & -0.473 & -0.061 & -0.204 & -0.978 & -0.364 \\
\hline 24 & Lingxian & -0.294 & -0.582 & -0.863 & -0.641 & -0.373 \\
\hline 25 & Yanggu & -0.568 & -0.891 & 0.083 & 0.363 & -0.388 \\
\hline 26 & Pingyuan & -0.299 & -0.517 & -1.111 & -0.733 & -0.398 \\
\hline 27 & Guanxian & -0.356 & -0.696 & -0.339 & -0.955 & -0.401 \\
\hline 28 & Wenshang & -0.743 & -0.893 & -0.047 & 0.598 & -0.474 \\
\hline 29 & Juancheng & -0.680 & -0.769 & -0.105 & -0.568 & -0.528 \\
\hline 30 & Dingtao & -0.862 & -0.595 & -0.264 & -0.197 & -0.584 \\
\hline
\end{tabular}

Extraction method: principal component analysis.

\subsubsection{Cluster Analysis}

Evaluate financial capacity of the major grain producing areas, we must start from the extracted public factors, combine with the reality, make deep analysis, thus to the four extracted common factors, using the set of connection between hierarchical do the cluster analysis, because the comprehensive factor score sorting ignores the personality and the common features of the financial ability of the various counties and cities, which contains in 
the explain factor, clustering analysis is a kind of supplement of sequence analysis, there is a big difference between operation results and comprehensive rank.

1) The first category. Jiyang, Laixi, Laizhou and Laishan. Besides Jiyang in the central region, the others are located in Shandong peninsula blue economic zone, comprehensive rank is different, but the structure of fiscal capacity factor is similar, namely the fiscal balance factor and self-financing factor are prominent, shows four counties have the ability to balance the budget, the self-sufficiency ability also performs well, but the environmental factor score is low, manifests short supply of the public service, it need to improve social environment. Laixi, Laizhou and Lai shan's economic development level is higher than other areas, so financial ability stronger than Jiyang, but they should focus on how to increase the financial input in livelihood, promote urban and rural integration, improve capital construction and the level of public services; Jiyang's economic is still cannot be compare with the above three counties, it should improve the economic environment of the whole county, attracting foreign investment, using radiation effect of Jinan, promote the development of urban and rural areas as a whole.

2) The second category. Huangdao, as a non-grain producing areas, ranked the first place, development factor is prominent. In recent years, relying on Qingdao's leading position, its economic growth is rapid, GDP in 2013 reached 212.4 billion, accounting for 25.5\% of Qingdao, is one of the most developed areas in Shandong province. But environmental factor is smaller, not match with economic development level, it restricts economic development potential. With the development of economy, the rapid increase of migrant workers, urban problems such as environment pollution, traffic congestion, began to emerge, the urban and rural public services is imbalance, environmental factor need to be improved.

3) The third category. Pingdu, Zhangqiu, Tengzhou, Zhucheng, Wenshang, Qufu, Feicheng, Yanggu, Zouping, Zhangdian, Taishan. In the structure of the county finance, environmental factor is bigger, but development factor, fiscal balance factor and self-financing factor are slightly low, but fiscal capacity of Zhangqiu, Pingdu, which are increasing significantly, even more than the central district of Zaozhuang, they accurately positioning of fiscal functions at the same time, put more money into the areas of the people's livelihood, improve the efficiency of the use of fiscal funds; Taishan, Qufu, Zhucheng, Zhangqiu and Pingdu's tourism have developed, the government attaches great importance to the infrastructure, increase investment in science and technology culture, also improve environmental factor. For the improvement of fiscal capacity, Tengzhou and Shizhong should cling to coal industry upgrade and industry structure adjustment of Zaozhuang, improve the economic development potential; Zhangqiu, Feicheng and Pingdu should rely on the good market location of Jinan, Taishan and Qingdao, vigorously develop characteristic agricultural products (such as Zhangqiu shallot, Feicheng peach, Pingdu daze mountain grape), keep special developing way of green agriculture, extend the industrial chain, increase added value of agricultural products. Wenshang and Yanggu financial ability is weak, in which development factor, balance factor and environment factor at a lower level. Although based on weak fiscal revenue sources, they should guarantee grain production firstly and put vigorously developing of the county economy in the top priority.

4) The fourth category. Daiyue, Cangshan, Junan, Qihe, Lingxian, Linyi, Pingyuan, Dongchang, Guanxian, Dongming, Juancheng and Dingtao. Besides Dongchang outshines the fiscal balance factor and environment factor, every other county four common factor is generally weak, especially in the development factor and self-financing factor, composite scores were negative. This kind of country is mostly traditional agricultural production in Shandong, especially the southwest of Shandong southwest, Dongming, Juancheng and Dingtao. It has the weakest financial ability and needs to strengthen the construction of government financial ability in the round. It is mainly limited by the economic development level. The shortage of the county financial resources affects the supply of public services, and infrastructure is not perfect and not attractive to foreign investment and becomes the bottleneck of restricting economic development in a vicious cycle of strife-torn.

\section{Conclusions and Suggestion}

Through factor analysis, it shows that the gap of financial capacity between east and west of Shandong grain producing areas is obvious. Major grain producing areas in East have strong ability. There is a more balance in central areas, but in western major grain producing areas, especially in the southwest, its financial capacity lags behind other areas in the province. The fiscal capacity is unbalanced not only between grain producing areas and non-grain producing areas, but also among grain producing areas. Through clustering analysis, the major grain producing areas' development factor and financially self-financing factor are key factors to restrict its fiscal ca- 
pacity. Non-grain producing areas' environmental factor doesn't match with its development level.

For the imbalance of major grain producing areas' fiscal capacity and the insufficiency of development factor and self-financing factor, the key is to solve the lack of financial resources. Suggestion as follows: First, taking advantage of local conditions, developing their own advantage industry, realizing the optimization and upgrading of industrial structure and promoting the economic sustainable development in an all-round way. Second, creating horizontal fiscal transfer payment system [20] and promoting equalization of the fiscal capacity. The tax reform occurred in 1994. Fiscal capacity is more unbalanced, but the practice proves that the fiscal transfer payment system of our country is remarkable to balance ability. It is advantageous to the fiscal equalization. Third, implementing PPP financing model, more cooperating social capital with the government and participating in the production and the supply of public goods.

\section{References}

[1] Gu, L.L. and Guo, Q.H. (2011) The Evolution and Develop Research of China’s Major Grain Producing Areas. Journal of Agricultural Economic Issues, 8, 4-9.

[2] Almond, G.A. (1966) Comparative Politics: A Development Approach Boston. Little, Brown \& Company, New York.

[3] Coleman, J.P. (1975) Local Government Viability. Chicago.

[4] Lenz, R.T. (1980) Strategic Capability: A Concept and Framework for Analysis. Academy of Management Review, 8, 20-23.

[5] Brown, A. (1980) Technical Assistance to Rural Communities: Stopgap or Capacity Building. Public Administration Review, 2, 6-9.

[6] Buchanan, J.M. (1950) The Pure Theory of Government Finance: A suggested Approach. Journal of Political Economy, 12, 32-35.

[7] Tibet (1956) A Pure Theory of Local Expenditures. Journal of Political Economy, 7, 22-24.

[8] Musgrave, R.A. (1959) The Theory of Public Finance. McGraw Hill, New York.

[9] Oates, W.E. (1972) Fiscal Federalism. Harcourt Brace Jovanovich, Orlando.

[10] Li, W.X. and Jiang, Y. (2002) The Theory Construction of Financial Capacity of Local Government. Nankai Economic Research, 11, 74-76.

[11] Li, X.J. and Liu, S.X. (2007) Local Government Fiscal Capacity Study. Journal of Financial Research, 9, 56-63.

[12] Lu, H.Y. and Jia, Z.L. (2009) China's Inspection and Evaluation of Local Government Financial Ability-Based on Factor Analysis of Provincial Data Comparison. Journal of Financial Research, 12, 82-88.

[13] Li, Q. (2004) China’s Fiscal Expenditure Research Gap between the Provinces. Journal of Economic Aspect, 3, 5-8

[14] Wu, X.L. and Deng, X.Y. (2006) Unbalance Fiscal Capacity. Journal of Statistics and Decision, 3, 83-85.

[15] Liu, H.B., Li, G. and Xia, Y.D. (2006) China’s County Fiscal Capacity. Journal of Financial Research, 5, 58-62.

[16] Ran, G.H., Lu, Z.Y. and Xu, K. (2011) Comparative Study Based on Factor Analysis of County Government Financial Ability: Example from Chongqing. Journal of Economic Management, 1, 22-28.

[17] Yang, L. and Yuan, X.Y. (2011) Survey Based on Factor Analysis of Fiscal Capacity. Journal of Local Finance Research, 1, 55-59.

[18] Xu, X.C. (2004) Study on Government Capacity of 16 Cities of the Yangtze River. Management World, 8, 18-27.

[19] Xin, F.K. (2014) Fiscal Decentralization, Fiscal Capacity, and Local Government Public Service Supply. Journal of Macroeconomic Research, 6, 67-77.

[20] Feng, H.B. (2013) Fiscal Equalization Theory and System Design. Journal of Contemporary Economic Studies, 8, 7681. 